\title{
Demographic, clinical and treatment characteristics of patients with Kaposi's sarcoma: A single-center study
}

\author{
Andac SALMAN (), Zuleyha OZGEN
}

\begin{abstract}
Objective: The clinical, demographic and treatment characheristics of patients with Kaposi's sarcoma (KS) are not well-defined. There is lack of consensus on treatment modalities. Thus, we aimed to define demographic, clinical characteristics and treatment outcomes in our cohort of patients with KS.

Patients and Methods: A retrospective cohort study was done and all patients who were followed up in our specialized cutaneous tumors outpatient clinic with a diagnosis of KS between 2006 and 2018 were included in the study.

Results: A total of 25 patients were included in the study. The mean age of the patients was 66 and $80 \%$ were male. The most common form of KS was classic type (80\%). During a mean follow-up of 43 months, the most frequently administered treatments were cryotherapy, interferons, radiotherapy, topical imiquimod and topical timolol. Overall a complete response was observed in $9(36 \%)$ patients.

Conclusion: The clinical and demographic characteristics of our cohort match those observed in existing literature. We think that the use of local treatments such as cryotherapy, topical imiquimod should be used more frequently in patients with limited disease. Considering the efficacy of timolol in other vascular tumors, future prospective studies investigating the effects of timolol in KS are highly warranted.
\end{abstract}

Keywords: Cryotherapy, Kaposi's sarcoma, Timolol, Treatment.

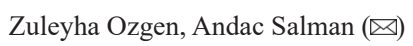

Department of Dermatology, School of Medicine, Marmara University Hospital, Pendik, Istanbul, Turkey

e-mail: asalmanitf@gmail.com
Accepted: 29.04.2019

\section{Introduction}

Kaposi's sarcoma (KS) is a malignant angiomatous neoplasia that was first described by Moritz Kaposi in 1872 [1]. Following the increased incidence of HIV infection and AIDS in 1980s, KS has drawn more attention as it became more frequent [1-3]. Immunosuppression and human herpes virus-8 (HHV-8) infection are the most commonly implicated etiological factors [2]. Kaposi's sarcoma is generally categorized into four subtypes: classic (sporadic), endemic (African), iatrogenic (immunosussant therapy related) and epidemic (AIDS related) [2,4]. The classic type of KS usually affects elderly males of Mediterranean or Middle Eastern descent. It usually presents with violaceous, red macules, patches, papules or nodules involving the lower extremities in all types. In addition, oral involvement and lymphedema are more commonly seen in epidemic and endemic forms, respectively. Visceral involvement most frequently occurs in the lungs and gastrointestinal tract and is usually seen in epidemic KS [2]. Restoring the immune system usually leads to improvement in iatrogenic and epidemic forms. Despite the lack of consensus on treatment of other forms; chemotherapy, radiotherapy, interferon, excision and imiquimod are among the reported treatment alternatives [2, 4-6].

Considering the limited data on demographic and clinical features of KS in our country and lack of studies investigating the treatment outcomes, in this study, we aimed to determine the demographic, clinical characteristics and treatment outcomes in our cohort of patients with KS of all forms.

\section{Patients and Methods}

A retrospective cohort study was done to evaluate the clinical and treatment characteristics of patients with KS. 
The medical records of the patients with histopathologically proven KS who were followed-up in our specialized cutaneous tumors outpatient clinic between 2006 and 2018 were retrospectively reviewed. The demographic (age, gender) and clinical (duration of disease, time to diagnosis, KS subtype, HIV status, site of involvement, mucosal and systemic involvement, comorbid systemic conditions, treatment modalities and outcomes, adverse effects) characteristics were recorded. In all patients HIV screening was done using Enzyme-linked Immunosorbent Assay (ELISA). Systemic involvement was determined with routine chest radiographs, fecal occult blood tests and lymph node examination. Further diagnostic procedures such as endoscopy or computed tomography scans were performed if needed. Response to treatment were defined as; complete response (complete resolution of all treated cutaneous lesions), partial response (incomplete resolution of cutaneous lesions) or no response (progression or no change in skin lesions). The study protocol was approved by the institutional review board (Approval number: 09.2019.520).

\section{Statistical analysis}

Statistical analysis was performed using SPSS version 23.0 (Statistical Package for Social Sciences, IBM, USA). Descriptive statistical methods were used in the analysis of the data. Numerical variables were shown as mean \pm standard deviation (range). Categorical variables were assessed by frequency analysis.

\section{Results}

This retrospective cohort study included 25 patients with KS who were being followed-up in our Specialized Cutaneous Tumors Outpatient Clinic. Among them 20 (80\%) patients were male, $5(20 \%)$ were female. The mean age of the patients was 66 (47-80). The mean follow-up duration was 43.6 (1-90) months. In all patients, the clinical diagnosis was confirmed with histopathological examination. The most frequent type of KS was the classic type seen in 20 $(80 \%)$ patients. Lymphedema of the lower extremities was present in $5(20 \%)$ patients, all having involvement of legs. The demographic and clinical characteristics of the patients were detailed in Table I.
Table I. Demographic and disease characteristics of the patients $(n=25)$.

\begin{tabular}{|c|c|c|c|c|}
\hline \multicolumn{5}{|l|}{ Characteristics } \\
\hline \multicolumn{3}{|c|}{ Mean age (years) Mean \pm SD (range) } & \multicolumn{2}{|c|}{$66.04 \pm 9.56(47-80)$} \\
\hline \multirow{2}{*}{ Gender n (\%) } & \multicolumn{2}{|c|}{ Female } & \multicolumn{2}{|c|}{$5(20)$} \\
\hline & \multicolumn{2}{|l|}{ Male } & \multicolumn{2}{|l|}{$20(80)$} \\
\hline \multicolumn{3}{|c|}{$\begin{array}{l}\text { Mean time elapsed until diagnosis } \\
\text { (months) } \\
\text { Mean } \pm \text { SD (range) }\end{array}$} & \multicolumn{2}{|l|}{$20.43 \pm 19.22(2-72)$} \\
\hline \multirow{4}{*}{$\begin{array}{l}\text { Comorbidities } \\
\text { n (\%) }\end{array}$} & $\begin{array}{l}\text { Coronary } \\
\text { artery disease }\end{array}$ & \begin{tabular}{|l|}
6 \\
$(24)$
\end{tabular} & Hyperlipidemia & $2(8)$ \\
\hline & Hypertension & $1(4)$ & HIV infection & $3(12)$ \\
\hline & $\begin{array}{l}\text { Diabetes } \\
\text { mellitus }\end{array}$ & $1(4)$ & $\begin{array}{l}\text { Renal } \\
\text { transplantation }\end{array}$ & $1(4)$ \\
\hline & $\begin{array}{l}\text { Crohn's } \\
\text { disease }\end{array}$ & $1(4)$ & None & $10(40)$ \\
\hline \multirow{4}{*}{$\begin{array}{l}\text { Kaposi type } \\
\text { n (\%) }\end{array}$} & \multicolumn{2}{|l|}{ Classic } & \multicolumn{2}{|l|}{$20(80)$} \\
\hline & \multicolumn{2}{|l|}{ Epidemic } & \multicolumn{2}{|l|}{$3(12)$} \\
\hline & \multicolumn{2}{|l|}{ Iatrogenic } & \multicolumn{2}{|l|}{$2(8)$} \\
\hline & \multicolumn{2}{|c|}{ Endemic } & \multicolumn{2}{|l|}{0} \\
\hline \multirow{5}{*}{$\begin{array}{l}\text { Site of } \\
\text { cutaneous } \\
\text { involvement } \\
\text { n (\%) }\end{array}$} & \multicolumn{2}{|c|}{ Lower extremities } & \multicolumn{2}{|l|}{$11(44)$} \\
\hline & \multicolumn{2}{|c|}{ Upper extremities } & \multicolumn{2}{|l|}{$1(4)$} \\
\hline & \multicolumn{2}{|c|}{$\begin{array}{l}\text { Lower and upper } \\
\text { extremities }\end{array}$} & \multicolumn{2}{|l|}{$8(32)$} \\
\hline & \multicolumn{2}{|c|}{$\begin{array}{l}\text { Lower extremities } \\
\text { and trunk }\end{array}$} & \multicolumn{2}{|l|}{$1(4)$} \\
\hline & \multicolumn{2}{|c|}{$\begin{array}{l}\text { Lower, upper } \\
\text { extremities and trunk }\end{array}$} & \multicolumn{2}{|l|}{$4(16)$} \\
\hline \multirow{2}{*}{$\begin{array}{l}\text { Mucosal } \\
\text { involvement } \\
\text { n (\%) }\end{array}$} & \multicolumn{2}{|c|}{$\begin{array}{l}\text { Present (oral } \\
\text { mucosa) }\end{array}$} & \multicolumn{2}{|l|}{$2(8)$} \\
\hline & \multicolumn{2}{|l|}{ Absent } & $23(92)$ & \\
\hline Systemic & Present (lympl & node) & $1(4)$ & \\
\hline $\begin{array}{l}\text { involvement } \\
\text { n (\%) }\end{array}$ & Absent & & $24(96)$ & \\
\hline $\begin{array}{l}\text { Mean duration } \\
\text { Mean } \pm \mathrm{SD} \text { (ran }\end{array}$ & follow-up (mo & nths) & $43.67 \pm 32.5(1-90$ & \\
\hline
\end{tabular}

Response to treatment was evaluated in 23 of 25 (92\%) patients. At least two different treatment modalities were used in 16 patients. At the time of the analysis, complete remission, was seen in 9 patients who had different combinations of treatment (39.1\%), whereas 14 patients $(60.9 \%)$ were on treatment with partial or no response. The most frequently administered treatment was cryotherapy. Twenty patients $(86.9 \%)$ were treated with cryotherapy and $8(40 \%)$ of them showed complete response, whereas a partial response was obtained in the remaining $12(60 \%)$ patients. Ten patients were given interferon alpha $2 \mathrm{a}$ which led to complete response only in $3(30 \%)$ patients. Complete response rates for other treatment modalities were as follows; radiotherapy (3/8), imiquimod $5 \%$ cream (1/6), timolol $0.5 \%$ solution (0/5), chemotherapy $(1 / 3)$ and surgical excision (2/2). Treatment outcomes were shown in Table II. 
Table II. Treatment outcomes in the study population.

\begin{tabular}{|l|l|l|l|l|}
\hline Treatment modality & $\mathbf{n}$ & $\begin{array}{l}\text { Complete } \\
\text { response } \\
\mathbf{( \% )}\end{array}$ & $\begin{array}{l}\text { Partial } \\
\text { response } \\
\mathbf{n}(\mathbf{\%})\end{array}$ & $\begin{array}{l}\text { No response } \\
\mathbf{n}(\mathbf{\%})\end{array}$ \\
\hline Cryotherapy & 20 & $8(40)$ & $12(60)$ & 0 \\
\hline Interferon alpha 2a & 10 & $3(30)$ & $5(50)$ & $2(20)$ \\
\hline Radiotherapy & 8 & $3(37.5)$ & $5(62.5)$ & 0 \\
\hline $\begin{array}{l}\text { Imiquimod 5\% } \\
\text { cream }\end{array}$ & 6 & $1(16.6)$ & $5(83.4)$ & 0 \\
\hline $\begin{array}{l}\text { Timolol 0.5\% } \\
\text { solution }\end{array}$ & 5 & 0 & 0 & $5(100)$ \\
\hline Chemotherapy* & 3 & $1(33.3)$ & $2(66.7)$ & 0 \\
\hline Surgical excision & 2 & $2(100)$ & 0 & 0 \\
\hline
\end{tabular}

(*: Single-agent chemotherapy with paclitaxel, etoposide or vincristine in one patient each)

All treatment modalities were generally well tolerated. The most commonly observed adverse effect was flu-like symptoms associated with interferon treatment (40\%). Only one patient had to discontinue interferon treatment due to flu-like symptoms, in the remaining three patients treatment was continued.

\section{Discussion}

The demographic and clinical characteristics of the patients with KS who were being followed-up in a tertiary referral center have been evaluated in the present study. The demographic and clinical features of our cohort match those observed in earlier studies. In addition, this study, to our knowledge, is one of the few studies from our country evaluating the outcomes of various treatment modalities in patients with KS.

The mean age of onset of KS may differ according to the subtype. Classic KS usually affects elderly males, whereas epidemic KS might present earlier [2, 4, 7]. The previous studies have reported a mean age of onset between 61 and 86 for classic KS [5, 8-13]. The mean age of onset in studies including patients with epidemic KS was between 34 and 55 [7, 14]. Accordingly, the mean age of our patients was 66. The vast majority of the existing studies have reported a male predominance [9-12], similar to our cohort with a male-to-female ratio of 4:1. Although, the rate of epidemic KS was reported as high as $80 \%$ in previous reports [7], only $12 \%$ of our patients were HIV seropositive. A possible explanation for this discrepancy might be the follow-up of the patients with epidemic KS in the Department of Infectious Diseases at our institution.
The mean time elapsed until diagnosis was 6 months in a previous report in which $50 \%$ of the patients had epidemic KS [6]. The longer time of delay (20 months) until diagnosis in our study might be attributed to the predominance of elderly patients with classic KS. Despite a long-time delay, the low prevalence of visceral involvement confirms the indolent course of classic KS. In accordance with the earlier studies, the most common site of involvement was lower extremities in this study $[11,12]$. In contrast to a previous study that reported 13\% mucosal involvement rate in classic KS [15], we did not observe mucosal involvement in patients with classic KS. This might be due to the lack of routine examination of mucosal surfaces in the clinical practice. Although, visceral involvement (lymph nodes, lungs, gastrointestinal system) rates up to $44 \%$ had been reported previously [8], only one patient had extracutaneous involvement in the current study. A high prevalence of type 2 diabetes mellitus in patients with KS had been reported $[11,16]$. Although, this study failed to demonstrate a similar association, systemic comorbidities were not uncommon in the present cohort. This might be of particular importance when treating these patients with systemic agents.

There is a lack of consensus-based treatment guidelines for KS, however, surgical excision, radiotherapy, cryotherapy, topical imiquimod, chemotherapy and interferon have all been used with various success in the literature [4, 17]. Accordingly, with the literature data, cryotherapy, interferon alpha 2a, radiotherapy and topical imiquimod were most frequently used treatment options in the present study. In our hands, cryotherapy, radiotherapy and surgical excision had provided the most favorable results in localized cutaneous lesions. Considering the age and systemic comorbidities of the patients, systemic chemotherapy and interferon might be preserved for patients with widespread, treatment resistant, symptomatic or extracutaneous disease. A novel aspect of the current study is the use of topical timolol which was previously reported in a limited number of case reports [1821]. Although, topical timolol failed to provide any beneficial effect in our patients, we believe that proper formulation for better penetration of the drug in hyperkeratotic lesions might have provided better outcomes. Considering the efficacy of topical timolol in infantile hemangioma [22], a pediatric vascular tumor, future studies investigating the efficacy of topical betablockers in KS would be of interest.

Some limitations of this study should be acknowledged. First, the study is limited by the use of retrospective design. 
Another limitation is that the number of patients was relatively small.

Nevertheless, this study extends our knowledge of demographic, clinical and treatment characteristics of patients with KS in our country. Although, no beneficial effect could be obtained, future prospective clinical studies investigating the efficacy of timolol in KS are warranted.

\section{Conflict of Interest}

The authors declare that there is no conflict of interest regarding the publication of this article.

\section{References}

1. Geraminejad P, Memar O, Aronson I, Rady PL, Hengge U, Trying SK. Kaposi's sarcoma and other manifestations of human herpesvirus 8. J Am Acad Dermatol 2002; 47:641-55. doi: $10.1067 / \mathrm{mjd} .2002 .128383$

2. Cesarman E, Damania B, Krown SE, Martin J, Bower M, Whitby D. Kaposi sarcoma. Nat Rev Dis Primers 2019; 5:9. doi: 10.1038/s41572.019.0060-9

3. Feuerman EJ, Potruch-Eisenkraft S. Kaposi's sarcoma. A follow-up of 38 patients. Dermatologica 1973; 146:115-22. doi: $10.1159 / 000252034$

4. Schneider JW, Dittmer DP. Diagnosis and treatment of Kaposi sarcoma. Am J Clin Dermatol 2017; 18:529-39. doi: $10.1007 / \mathrm{s} 40257.017 .0270-4$

5. Kandaz M, Bahat Z, Guler OC, Canyilmaz E, Melikoglu M, Yoney A. Radiotherapy in the management of classic Kaposi's sarcoma: A single institution experience from Northeast Turkey. Dermatol Ther 2018; 31:1-4. doi: 10.1111/ dth. 12605

6. Chalya PL, Mbunda F, Rambau PF, et al. Kaposi's sarcoma: A 10-year experience with 248 patients at a single tertiary care hospital in Tanzania. BMC Res Notes 2015; 8:1-10. doi: 10.1186/s13104.015.1348-9

7. Tiussi RM, Caus AL de O, Diniz LM, Lucas EA. Kaposi's sarcoma: clinical and pathological aspects in patients seen at the Hospital Universitário Cassiano Antônio Moraes Vitória - Espírito Santo - Brazil. An Bras Dermatol 2012; 87:220-7. doi: 10.1590/S0365.059.6201200.020.0005

8. Errihani H, Berrada N, Raissouni S, Rais F, Mrabti H, Rais G. Classic Kaposi's sarcoma in morocco: Clinico epidemiological study at the national institute of oncology. BMC Dermatol 2011; 11:15. doi: 10.1186/1471-5945-11-15

9. Wu X-J, Kang X-J, An C-X, et al. One hundred and five Kaposi sarcoma patients: a clinical study in Xinjiang, Northwest of China. J Eur Acad Dermatol Venereol 2013; 28:1545-52. doi: 10.1111/jdv.12349

10. Trinca S, Ricci P, Benedetti M, Trinca S, Ricci P, Comba P. High incidence of classic Kaposi's sarcoma in Mantua,
Po Valley, Northern Italy (1989-1998). Br J Cancer 2002; 85:379-82. doi: 10.1054/bjoc.2001.1912

11. Su Ö, Onsun N, Arda H, Ümmetoğlu Ö, Pekdemir A. Clinical Features, Presence of Human Herpesvirus- 8 and Treatment Results in Classic Kaposi Sarcoma. TURKDERM - Arch Turkish Dermatology Venerol 2008; 42:122-6

12. Gülüş Demirel B, Koca R, Solak Tekin N, Onak Kandemir N, Doğan Gün B, Köktürk F. Classic Kaposi's sarcoma: The clinical, demographic and teratment characteristics of seventy-four patients. TURKDERM - Arch Turkish Dermatology Venerol 2016; 50:136-40. doi: 10.4274/ turkderm.35336

13. Demirkazik A, Ozal G, Yildirim Ozdemir N, et al. Fifty-one Kaposi sarcoma patients. Clin Transl Oncol 2010; 12:629 33. doi: 10.1007/s12094.010.0568-7

14. Laresche C, Fournier E, Dupond AS, et al. Kaposi's sarcoma: a population-based cancer registry descriptive study of 57 consecutive cases diagnosed between 1977 and 2009. Int J Dermatol 2014; 53:e549-54. doi: 10.1111/ijd.12453

15. Cottoni F, Masala MV, Piras P, Montesu MA, Cerimele D. Mucosal involvement in classic Kaposi's sarcoma. Br J Dermatol 2003; 148:1273-4. doi: 10.1046/j.13652133.2003.05359.x

16. DiGiovanna JJ, Safai B. Kaposi's sarcoma. Retrospective study of 90 cases with particular emphasis on the familial occurrence, ethnic background and prevalence of other diseases. Am J Med 1981; 71:779-83. doi: 10.1016/00029343(81)90356-9

17. Régnier-Rosencher E, Guillot B, Dupin N. Treatments for classic Kaposi sarcoma: A systematic review of the literature. J Am Acad Dermatol 2013; 68:313-31. doi: 10.1016/j. jaad.2012.04.018

18. Alcántara-Reifs CM, Salido-Vallejo R, Garnacho-Saucedo GM, Vélez García-Nieto A. Classic Kaposi’s sarcoma treated with topical 0.5\% timolol gel. Dermatol Ther 2016; 29:30911. doi: $10.1111 /$ dth. 12381

19. Meseguer-Yebra C, Cardeñoso-Álvarez ME, Bordel-Gómez MT, Fraile-Alonsı MC, Perez-Losada ME, Sanchez-Estella J. Successful treatment of classic Kaposi sarcoma with topical timolol: report of two cases. Br J Dermatol 2015; 173:860-2. doi: 10.1111/bjd.13746

20. Chap S, Vu M, Robinson AJ, Braue A, Varigos GA, Scardamaglia L. Treatment of cutaneous iatrogenic Kaposi sarcoma with topical timolol. Australas J Dermatol 2017; 58:242-3. doi: 10.1111/ajd.12650

21. Abdelmaksoud A, Filoni A, Giudice G, Vestita M. Classic and HIV-related Kaposi sarcoma treated with $0.1 \%$ topical timolol gel. J Am Acad Dermatol 2017; 76:153-5. doi: 10.1016/j.jaad.2016.08.041

22. Puttgen K, Lucky A, Adams D, et al. Topical Timolol Maleate Treatment of Infantile Hemangiomas. Pediatrics 2016; 138:e20160355-e20160355. doi: 10.1542/peds.2016035529:309-11

23. Puttgen K, Lucky A, Adams D, et al. Topical Timolol Maleate Treatment of Infantile Hemangiomas. Pediatrics 2016; 138:e20160355-e20160355 